\title{
A Guinea Pig Model for the Identification of In Utero Alcohol Exposure Using Fatty Acid Ethyl Esters in Neonatal Hair
}

\author{
DANIELA L. CAPRARA, JAMES F. BRIEN, UMAR IQBAL, JAMES N. REYNOLDS, JULIA KLEIN, \\ AND GIDEON KOREN
}

Division of Clinical Pharmacology and Toxicology [D.L.C., J.K., G.K], The Hospital for Sick Children, Toronto, Ontario M5G 1X8, Canada; Department of Pharmacology and Toxicology [ J.F.B., U.I., J.N.R.], Faculty of Health Sciences, Queen's University, Kingston, Ontario K7L 3N6, Canada

\section{ABSTRACT}

\begin{abstract}
Measuring levels of fatty acid ethyl esters (FAEE) in hair has been a useful way to discriminate between adult heavy and nondrinkers. Extending the use of FAEE into neonatal hair to objectively identify children exposed to alcohol in utero may revolutionize current methods used to diagnose fetal alcohol spectrum disorder (FASD). Here we confirm for the first time that chronic exposure to alcohol during pregnancy in guinea pigs leads to increased levels of FAEE in both maternal and neonatal hair. The mean cumulative FAEE concentration in exposed maternal samples taken at GD57 was $0.431 \pm 0.140 \mathrm{pmol} / \mathrm{mg}$ (mean $\pm \mathrm{SEM}$ ); levels observed in corresponding sucrose and water controls were 10-fold lower. Similarly, FAEE concentrations in exposed offspring samples taken at postnatal d 1 (mean cumulative FAEE $=0.491 \pm 0.177 \mathrm{pmol} / \mathrm{mg}$ ) were more than 15 -fold higher than control counterparts. Sixty percent of all alcohol-exposed animal samples contained two or more quantifiable FAEE, whereas close to $90 \%$ of either water or sucrose control samples did not have more than one quantifiable level of
\end{abstract}

a single FAEE. Results of this study suggest that FAEE in neonatal hair may be useful biomarkers in identifying in utero alcohol exposure and may facilitate the early diagnosis and treatment of FASD. (Pediatr Res 58: 1158-1163, 2005)

Abbreviations
E14, ethyl myristate
E16, ethyl palmitate
E18, ethyl stearate
E18:1, ethyl oleate
EI, electron impact ionization
FAEE, fatty acid ethyl esters
FASD, fetal alcohol spectrum disorder
GC/MS, gas chromatography/mass spectrometry
GD, gestational day
SPE, solid-phase extraction

Ethanol consumption is common among young women of reproductive age. Thus, the chance of a mother inadvertently exposing her developing fetus to alcohol in early pregnancy is high. Although ethanol is a well-established teratogenic drug responsible for increased miscarriages, still births, malformations, and dysfunction (1), approximately $20 \%$ of pregnant women continue to drink into their pregnancy, $4 \%$ at heavy levels (2). Additionally, recent years have shown an increase in binge drinking during pregnancy, from $0.7 \%$ to $2.9 \%$ (3). Consequently, the effects of in utero alcohol exposure have increasingly become a significant public health concern.

Received February 16, 2005; accepted May 6, 2005.

Correspondence: Gideon Koren, M.D., Division of Clinical Pharmacology/Toxicology The Hospital for Sick Children 555 University Ave., Toronto, Ontario M5G 1X8, Canada; e-mail: gkoren@sickkids.ca

This work was supported by grants from the Canadian Institutes for Health Research and the Ontario Graduate Scholarship program. G.K. holds the Ivey Chair in Molecular Toxicology, The University of Western Ontario.

DOI: 10.1203/01.pdr.0000185201.83801.ed
Prenatal alcohol exposure can be associated with a range of effects known as FASD. Fetal alcohol syndrome is found at the most severe end of the spectra and diagnosis is typically comprised of prenatal and postnatal growth restriction, typical facial dysmorphology, and a pervasive pattern of neurocognitive and behavioral dysfunction (2). One of the most difficult issues regarding FASD lies in the diagnosis of milder forms of the disorder where no physical markers have manifested. Without maternal confirmation of ethanol exposure, the majority of these cases go undetected until the children have begun their schooling, when the effects of brain dysfunction become apparent (4).

Due to denial, embarrassment, and litigious fears, maternal reports of gestational drinking are often inaccurate or not available (5). Establishing a biologic marker of fetal exposure to ethanol is therefore a critical step in ensuring FASD diagnosis for millions of neonates and young children worldwide.

FAEE are nonoxidative metabolites of ethanol. Unlike ethanol and acetyl aldehyde, FAEE have the potential to accumu- 
late in body fluids and tissue for extended periods of time and have emerged as potential markers for chronic alcohol exposure $(6,7)$. Accumulation of FAEE in neonatal meconium has high sensitivity and specificity in detecting excessive maternal drinking and correlates well with neurodevelopmental disabilities $(9,10)$. However, one of the major limitations with meconium analysis is that this matrix is available only during the first 2-3 d of life and hence has a very narrow window of opportunity for collection. Consequently, diagnosis of maternal drinking may be missed thereafter.

Unlike meconium, neonatal hair collection can occur up to 3 mo after birth. Thus, measurements of FAEE in this matrix can become a powerful tool in the detection of in utero alcohol exposure and in the subsequent diagnosis of FASD. As a result of their hydrophobic nature, FAEE have the potential to accumulate significantly into the hair and remain for the life of the hair or until it is cut $(10)$. Pragst and colleagues $(11,12)$ have found increased FAEE concentrations in the hair of adult alcoholics. Using headspace solid-phase microextraction and GC/MS, they succeeded in developing a reliable and sensitive method for the routine analysis of E14, E16, E18, and E18:1 in adult hair. E16 and E18:1 were found in the highest concentrations, with means of 5.94 and $7.08 \mathrm{pmol} / \mathrm{mg}$ of hair, respectively. In contrast, hair taken from children and teetotallers failed to yield detectable levels of FAEE (12). For social drinkers, defined as an alcohol consumption of approximately two to four standard drinks per week, levels of FAEE were much lower than what was seen in alcoholic samples, with maximum E16 and E18:1 levels of 1.40 and $1.03 \mathrm{pmol} / \mathrm{mg}$. These results provide evidence that the measurement of FAEE concentrations in hair can be used as biologic markers for excessive alcohol consumption in adults.

A case study using the method described by Pragst et al. (9) has revealed that FAEE are present in the hair of neonates exposed to alcohol prenatally. Klein et al. $(8,9)$ have documented the presence of significant levels of FAEE in the hair of an admitted gestational drinker and her neonate. Both maternal and newborn hair samples were positive for FAEE, at 2.6 and $0.4 \mathrm{pmol} / \mathrm{mg}$, respectively. This case report indicates that neonatal hair analysis of FAEE may hold much promise as a potential biomarker for in utero alcohol exposure. To date, no such test has been developed and/or validated.

Our objective in this present study was to establish whether FAEE accumulate in neonatal hair in a reproducible and predictable manner after chronic prenatal ethanol exposure. We used guinea pigs as an experimental animal to investigate the potential of FAEE in neonatal hair since, similar to humans and unlike rats and mice, pups are born with hair that grows in utero. We have wide experience in the pharmacokinetics of ethanol in pregnant guinea pigs, with measured maternal ethanol blood concentrations corresponding to those shown in alcoholic mothers $(2,13,14)$. Furthermore, we have used this model successfully in studying ethanol teratogenesis (15-17). Using this animal model of gestational alcohol exposure, we may provide needed insight into the feasibility of using FAEE in neonatal hair as potential biomarkers for in utero alcohol exposure.

\section{METHODS}

Human adult hair samples for characterization of FAEE and analytical method. Human adult hair samples were obtained from subjects, as approved by the local ethics commission at the Hospital for Sick Children. Subjects were anonymously asked to complete a brief questionnaire regarding their drinking history and weekly pattern of alcohol consumption over the previous year. Guidelines from the Centre of Addiction and Mental Health (CAMH) in Toronto, Ontario, were used to define heavy drinkers as males drinking more than 14 standard drinks of alcohol per week and females drinking more than 9 standard drinks of alcohol per week. Nondrinkers were defined as individuals who abstained completely from alcohol consumption in the previous year. These collected samples were used to help develop and validate the assay for the measurement of FAEE in hair.

Treatment animals. The following experimental protocol was approved by the Queen's University Animal Care Committee: Female nulliparous DunkinHartley strain guinea pigs (Charles River Canada Inc., St-Constant, Quebec), approximately $600 \mathrm{~g}$ body weight, were bred using an established procedure. Gestational day (GD) 0 was defined as the last day of full vaginal membrane opening, whereas term was at approximately GD 68. Animals were housed in separate cages with a 12-h light/dark cycle at an ambient temperature of $23^{\circ} \mathrm{C}$.

Animals were separated into the following treatment groups: a) $4 \mathrm{~g}$ of ethanol (30\% vol/vol)/kg maternal body weight/day with ad libitum access to food and water; b) isocaloric sucrose $(42 \% \mathrm{wt} / \mathrm{vol})$ with pair-feeding to an ethanol treated animal and ad libitum access to water; c) isovolumetric water with ad libitum access to food and water. Daily treatments involved two equally divided doses separated by $2 \mathrm{~h}$ every day from GD 2 to GD 67. Blood ethanol concentrations were determined using a gas-liquid chromatographic method (18).

Hair sample collection. Hair samples were taken from pregnant mothers at GD 57 and 65, as well as from offspring at postnatal day (PD) 1 and 10. Due to sample weight restrictions, hair from pups at PD1 was pooled together for each litter. Hair collection was performed concurrently with daily animal weighing to avoid additional stress to the animals. A total of $\sim 50 \mathrm{mg}$ of hair was collected per time point and this involved two to three small cuts with scissors. Samples were placed in 1.5-mL Eppendorf tubes and stored at room temperature until time of analysis.

Sample preparation and SPE. Approximately $20 \mathrm{mg}$ of each dry hair sample was weighed out into $15-\mathrm{mL}$ extraction vials and cut into pieces of 1-3 $\mathrm{mm}$ in length. Fifty microliters of internal standard (heptadecanoic acid ethyl ester, $1.0 \mu \mathrm{g} / \mathrm{mL}$ ) was added to each sample. The vials were then capped and shaken vigorously for 5 min with a gel Surfer shaker at $85 \%$ of maximum speed. To quantify FAEE, for each batch of samples analyzed a five-point calibration curve was prepared by adding specified amounts of the 6 FAEE [lauric (E12), E14, palmitoleic (E16:1), E16, E18, and E18:1, 0.01-1.0 $\mu \mathrm{g} / \mathrm{mL}$ ] to calibration samples (CS).

The overnight hair extraction procedure was modified from that establish by Pragst et al. (12). To each spiked hair sample, $4.0 \mathrm{~mL}$ of hexane and $0.5 \mathrm{~mL}$ of DMSO were added. Vials were closed with their cap and sealed tightly using parafilm. The mixture was shaken for $16 \mathrm{~h}$ at $25^{\circ} \mathrm{C}$. After overnight extraction, liquid from the mixture was transferred to a $10-\mathrm{mL}$ conical centrifuge tube and centrifuged with a Beckham GS-6R centrifuge for $15 \mathrm{~min}$ at $3000 \mathrm{rpm}, 4^{\circ} \mathrm{C}$. The top hexane layer was then separated into a clean test tube and evaporated under $\mathrm{N}_{2}$ at $35^{\circ} \mathrm{C}$. Residue was reconstituted with $1 \mathrm{~mL}$ of hexane.

SPE was performed following a method modified from Chan et al. (19). Briefly, $\mathrm{NH}_{2}$ columns were activated with $1 \mathrm{~mL}$ of hexane and transferred to a new clean test tube where reconstituted samples were loaded. Samples were eluted with $2 \mathrm{~mL}$ of hexane and liquid was collected and evaporated under $\mathrm{N}_{2}$ at $35^{\circ} \mathrm{C}$. Samples then went through a reconstitution with $1 \mathrm{~L}$ of fresh hexane and evaporation, followed by a final reconstitution with $50 \mu \mathrm{L}$ of hexane. Final extracts were transferred into glass inserts and placed and sealed into amber GC/MS vials. Final calibration concentrations ranged from $1.0 \mathrm{ng} / \mathrm{mL}$ to $500 \mathrm{ng} / \mathrm{mL}$.

$\boldsymbol{G C} / \boldsymbol{M S}$. A Varian Saturn 2100T GC/MS/MS with an ion trap mass spectrometer was used for GC-MS analysis. Injection of $2 \mathrm{uL}$ of sample was performed by a Varian CP-8400 autosampler (Varian, Palo Alto, CA). A CPSil-8 low-bleed/MS, fused silica chrompack capillary column $(30 \mathrm{~m} \times 0.25$ $\mathrm{mm} \times 0.25 \mathrm{um}$, Varian) with helium carrier gas $(1.0 \mathrm{~mL} / \mathrm{min})$ was used for GC separation. The following GC oven temperature program was applied: 2 min at $100^{\circ} \mathrm{C}$, then $20^{\circ} \mathrm{C} / \mathrm{min}$ up to $300^{\circ} \mathrm{C}$, then $18 \mathrm{~min}$ at $300^{\circ} \mathrm{C}$. Due to the high fragmentation potential of FAEE, the MS analysis was performed in chemical ionization mode using isobutane as the ionizing gas. The temperatures of the injector, the transfer-line, the manifold, and the trap were $260^{\circ} \mathrm{C}, 300^{\circ} \mathrm{C}, 50^{\circ} \mathrm{C}$, and $220^{\circ} \mathrm{C}$, respectively.

Data analysis. Using five-point calibration curves, the six individual FAEE were identified and quantified. Results were expressed in picomoles per milligram of hair. Statistical analysis was performed using SigmaStat 2.03 
statistical software (SPSS Inc., Chicago, IL). Differences in mean FAEE levels between ethanol-treated pups and sucrose/water controls, at each collection time point, were assessed using $t$ tests for normally distributed data and Mann-Whitney rank sum tests for nonparametric data. Differences between the two control groups were similarly assessed.

\section{RESULTS}

Characterization of FAEE and analytical method. Using GC/MS in chemical ionization (CI) mode, with isobutane as the ionizing gas, each FAEE included in the analysis was characterized. Molecular weight, quantification and qualifier ions along with retention times for the internal standard and all six FAEE are listed in Table 1.

For calibration, 20-mg samples of the teetotaler hair were spiked with five concentrations between 0.001 and 0.500 $\mu \mathrm{g} / \mathrm{mL}$ of the six FAEE. Using quantification ions, five-point calibration curves were generated for each FAEE. Curves were linear for the concentration ranges used and correlation coefficients typically ranged from 0.950 to 0.998 for each batch of samples analyzed. Data for limits of detection (LOD), limits of quantification (LOQ), extraction efficiencies, and variation for each FAEE analyzed are presented in Table 2 and Table 3. LOD values were between $<0.008 \mathrm{pmol} / \mathrm{mg}$ for ethyl stearate and $0.022 \mathrm{pmol} / \mathrm{mg}$ for ethyl laurate. Corresponding LOQ values ranged between $0.008 \mathrm{pmol} / \mathrm{mg}$ and $0.055 \mathrm{pmol} / \mathrm{mg}$. Extraction efficiencies and coefficients of variation $(\% \mathrm{CV})$ were calculated for a low $(0.1 \mu \mathrm{g} / \mathrm{mL})$, medium $(0.5 \mu \mathrm{g} / \mathrm{mL})$, and high $(2.0 \mu \mathrm{g} / \mathrm{mL})$ concentration level.

To evaluate the sensitivity of the developed assay, hair samples from four heavy drinkers and three nondrinkers were analyzed and results compared. Each sample was measured in duplicate. All nondrinkers claimed to have abstained from alcohol consumption for at least $1 \mathrm{y}$. Average alcohol consumption for heavy drinking subjects ranged from 21 to 168 standard drinks per week. A significant difference was found in the mean total FAEE concentration between heavy drinking and nondrinking cohorts. Heavy drinkers yielded a mean level of $6.33 \pm 1.03 \mathrm{pmol} / \mathrm{mg}$ whereas only one of the nondrinkers generated a measurable FAEE concentration ( mean $_{\text {nondrinkers }}=$ $0.01 \pm 0.01 \mathrm{pmol} / \mathrm{mg}$ ). Variation between duplicates ranged from 0.0 to $38.6 \%$ and may be due to variation in matrix concentrations of FAEE within the same sample.

Guinea pig maternal hair samples. A total of nine chronic ethanol-treated, six isocaloric sucrose-treated, and five isovolumetric water-treated female guinea pigs were included in the study. No differences were seen between maternal sucrose and

Table 1. Individual FAEE molecular weights, retention times, and quantification/qualifier ions used in hair analysis

\begin{tabular}{lccc}
\hline \multicolumn{1}{c}{ FAEE } & $\begin{array}{c}\text { Molecular } \\
\text { weight } \\
(\mathrm{g} / \mathrm{mol})\end{array}$ & $\begin{array}{c}\text { Approx. } \\
\text { retention } \\
\text { time (min) }\end{array}$ & Ions \\
\hline Lauric (E12) & 228.4 & 7.55 & 229,227 \\
Myristic (E14) & 256.4 & 8.71 & 257,255 \\
Palmitoleic (E16:1) & 282.5 & 9.66 & 283,284 \\
Palmitic (E16) & 284.5 & 9.75 & 285,286 \\
Heptadecanoic IS & 298.5 & 10.25 & $299,300,297,298$ \\
Oleic (E18:1) & 310.5 & 10.60 & 311,312 \\
Stearic (E18) & 312.5 & 10.70 & 313,314 \\
\hline
\end{tabular}

Quantification ions are expressed in italics.
Table 2. Limit of detection ( $L O D)$ and limit of quantification (LOQ) for each individual FAEE included in analysis

\begin{tabular}{lcc}
\hline \multicolumn{1}{c}{ FAEE } & LOD (pmol/mg) & LOQ (pmol/mg) \\
\hline Lauric (E12) & 0.022 & $0.055-0.219$ \\
Myristic (E14) & $<0.010$ & $0.010-0.049$ \\
Palmitoleic (E16:1) & 0.018 & $0.044-0.177$ \\
Palmitic (E16) & $<0.009$ & $0.009-0.044$ \\
Oleic (E18:1) & $<0.008$ & $0.008-0.040$ \\
Stearic (E18) & $<0.008$ & $0.008-0.040$ \\
\hline
\end{tabular}

Table 3. Extraction efficiencies (EE) and percentage coefficient of variation $(\mathrm{CV})$ for each individual FAEE included in analysis

\begin{tabular}{|c|c|c|c|c|}
\hline FAEE & $\begin{array}{c}\% \mathrm{EE}_{[\text {low] }} \\
(\% \mathrm{CV})\end{array}$ & $\begin{array}{c}\% \mathrm{EE}_{[\text {[medium] }} \\
(\% \mathrm{CV})\end{array}$ & $\begin{array}{c}\% \mathrm{EE}_{[\text {high] }} \\
(\% \mathrm{CV})\end{array}$ & $\begin{array}{l}\text { Instrumental } \\
\% \mathrm{CV}_{\text {[medium] }}\end{array}$ \\
\hline Lauric (E12) & $56.55(29.39)$ & $43.68(30.02)$ & $46.24(12.13)$ & 7.30 \\
\hline Myristic (E14) & $42.76(6.13)$ & $39.31(7.61)$ & $51.90(8.15)$ & 10.60 \\
\hline $\begin{array}{l}\text { Palmitoleic } \\
\text { (E16:1) }\end{array}$ & $40.55(9.09)$ & $56.01(9.09)$ & $75.68(4.20)$ & 6.54 \\
\hline Palmitic (E16) & $39.21(8.18)$ & $62.69(12.98)$ & $58.89(2.55)$ & 10.75 \\
\hline Oleic (E18:1) & $31.37(8.61)$ & $52.46(12.34)$ & $73.04(6.56)$ & 6.95 \\
\hline Stearic (E18) & 30.18 (17.75) & $56.59(8.96)$ & $67.14(10.42)$ & 9.03 \\
\hline
\end{tabular}

$[$ low $]=0.10 \mu \mathrm{g} / \mathrm{mL} ;[$ medium $]=0.50 \mu \mathrm{g} / \mathrm{mL} ;[$ high $]=2.0 \mu \mathrm{g} / \mathrm{mL}$.

water samples. Mothers exposed to sucrose or water had invariable hair levels of FAEE $<0.28 \mathrm{pmol} / \mathrm{mg}$. Overall, ethanol-treated mothers had 10-fold higher levels of FAEE compared with their controls (Table 4, Fig. 1A). A significant difference in the mean cumulative FAEE concentration between ethanol-exposed mothers and their sucrose controls was seen with samples taken at GD57 $(p=0.021)$.

Guinea pig neonatal hair samples. A total of 26 ethanolexposed, 16 sucrose control, and 18 water control offspring were born into the study. The number of pups per litter along with their ranges of cumulative FAEE concentrations for each treatment group are listed in Table 5. No differences were seen in FAEE levels between neonatal sucrose and water samples. Similar to maternal hair samples, neonates exposed to sucrose or water also had invariable hair levels of FAEE $<0.10$ $\mathrm{pmol} / \mathrm{mg}$.

Overall, ethanol-exposed pups had a 15-fold higher cumulative FAEE level than their sucrose and water controls (Table 4, Fig. 1B). A significant difference in the mean cumulative FAEE concentration between ethanol-exposed pups and their sucrose controls was seen with samples taken at PD1, at 0.491 $\mathrm{pmol} / \mathrm{mg}$ and $0.007 \mathrm{pmol} / \mathrm{mg}$, respectively $(p=0.046)$. A similar difference was seen in PD10 FAEE levels between ethanol-exposed pups and both water and sucrose controls $(p<$ $0.001)$.

Looking at both maternal and neonatal samples, ethyl stearate and ethyl oleate were the most prevalent FAEE quantified. Overall, ethanol-exposed animals exhibited an analysis pattern containing higher numbers of FAEE. Sixty-eight percent of all alcohol-exposed animal samples contained two or more different FAEE; $\sim 90 \%$ of either sucrose or water control animal samples did not have more than one quantifiable level of all six FAEE analyzed (Fig. 2). 
Table 4. Comparisons of total FAEE concentrations between treatment groups for each sampling time

\begin{tabular}{cccccc}
\hline $\begin{array}{c}\text { Treatment group/ } \\
\text { sampling time }\end{array}$ & $\begin{array}{c}\text { Ethanol } \\
\text { (pmol/mg) }\end{array}$ & $\begin{array}{c}\text { Sucrose } \\
\text { (pmol/mg) }\end{array}$ & $\begin{array}{c}p \text { Value* } \\
\text { (95\% confidence interval) }\end{array}$ & $\begin{array}{c}\text { Water } \\
\text { (pmol/mg) }\end{array}$ & $\begin{array}{c}p \text { Value* } \\
\text { (95\% confidence interval) }\end{array}$ \\
\hline GD57 & $0.431 \pm 0.140$ & $0.048 \pm 0.045$ & $0.021(-0.002$ to 0.767$)$ & $0.058 \pm 0.017$ & $0.072(-0.039$ to 0.800$)$ \\
GD65 & $0.468 \pm 0.143$ & $0.084 \pm 0.084$ & $0.118(-0.115$ to 0.882$)$ & $0.057 \pm 0.034$ & $0.060(-0.021$ to 0.838$)$ \\
PD1 & $0.491 \pm 0.117$ & $0.007 \pm 0.007$ & $0.046(0.010$ to 0.960$)$ & $0.060 \pm 0.035$ & $0.082(-0.068$ to 0.989$)$ \\
PD10 & $0.591 \pm 0.123$ & $0.051 \pm 0.024$ & $<0.001(0.220$ to 0.860$)$ & $0.058 \pm 0.017$ & $<0.001(0.229$ to 0.837$)$ \\
\hline
\end{tabular}

GD57 and GD65 samples taken from maternal animals. PD1 and PD10 samples taken from offspring. Values expressed as mean cumulative FAEE in pmol/mg of hair \pm SEM. No significant differences noted between sucrose and water control groups.

$* p$ Values express differences between ethanol group and sucrose/water; significant $p$ value $\leq 0.05$.
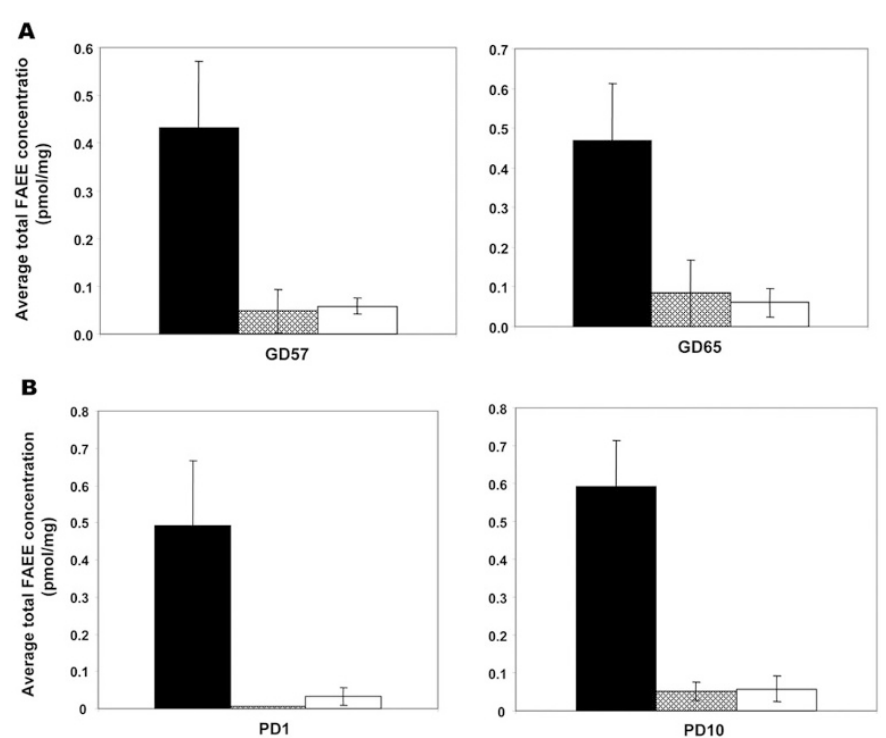

Figure 1. Average total FAEE concentration is significantly higher in ethanol-treated animals in comparison to their controls. (A) FAEE levels found in maternal samples taken at gestational day (GD) 57 and 65 . Nine chronic ethanol- treated, six isocaloric sucrose-treated, and five isovolumetric watertreated female guinea pigs were included in the study. $(B)$ FAEE levels found in neonatal samples taken at postnatal day (PD) 1 and 10. Twenty-six ethanolexposed, 16 sucrose control, and 18 water control offspring were born into the study. Data expressed in mean \pm SEM. No significant differences found between sucrose and water control groups. (ם) Ethanol-treated animals, (网) isocaloric sucrose controls, $(\square)$ isovolumetric water controls.

\section{DISCUSSION}

In investigating the possibility of using FAEE levels in neonatal hair as a means to identify in utero alcohol exposure, we have successfully developed a sensitive and reliable method for the measurement of FAEE in hair. Our assay is novel in that it combines the use of SPE with GC/MS/CI. SPE has been used extensively in the isolation of FAEE from matrices such as blood, tissue, and meconium (19-21). However, here we demonstrate for the first time its use in isolating FAEE from hair.

Previous assays used for the detection of FAEE in hair have implemented GC/MS with electron impact ionization (EI) to identify and quantify isolated FAEE (12). GC/MS identifies compounds based on their characteristic ions and fragmentation patterns. EI involves high-energy treatment, which typically leads to an extensive fragmentation of FAEE to lowmass, nondescriptive hydrocarbon fragments (22). Because EI yields identical fragmentation patterns for the various FAEE, spectrometric confirmation of these compounds using $\mathrm{GC} /$ MS/EI may be difficult. In contrast, CI using isobutane is a "softer" ionization mode and forms virtually only $\mathrm{M}+1$ ions
Table 5. Litter characteristics for ethanol-treated, isocaloric sucrose, and isovolumetric water guinea pig offspring including FAEE ranges found within each litter

\begin{tabular}{lccc}
\hline Litter code & $\begin{array}{c}\text { Number } \\
\text { of pups }\end{array}$ & $\begin{array}{c}\text { Mean number of } \\
\text { pups }( \pm \text { SD) }\end{array}$ & $\begin{array}{c}\text { FAEE range } \\
(\mathrm{pmol} / \mathrm{mg})\end{array}$ \\
\hline Ethanol 1 & 4 & & $<$ LOQ-1.776 \\
Ethanol 2 & 4 & & $0.202-1.605$ \\
Ethanol 3 & 3 & & $<\mathrm{LOQ}$ \\
Ethanol 6 & 3 & & $<$ LOQ-0.377 \\
Ethanol 7 & 3 & $3.0 \pm 1.3$ & $0.022-1.972$ \\
Ethanol 8 & 5 & & $0.238-0.795$ \\
Ethanol 9 & 1 & & $\mathrm{n} / \mathrm{a}$ \\
Ethanol 10 & 3 & & $0.520-1.112$ \\
Ethanol 11 & 1 & & $\mathrm{n} / \mathrm{a}$ \\
Sucrose 1 & 4 & & $0.038-0.372$ \\
Sucrose 2 & 3 & & $<\mathrm{LOQ}$ \\
Sucrose 3 & 5 & $2.8 \pm 1.6$ & $<\mathrm{LOQ}-0.158$ \\
Sucrose 4 & 3 & & $<\mathrm{LOQ}$ \\
Sucrose 5 & 1 & & $\mathrm{n} / \mathrm{a}$ \\
Sucrose 8 & 1 & & $\mathrm{n} / \mathrm{a}$ \\
Water 1 & 3 & & $<\mathrm{LOQ}$ \\
Water 2 & 5 & & $<\mathrm{LOQ}-0.598$ \\
Water 3 & 3 & $3.6 \pm 0.8$ & $<\mathrm{LOQ}-0.009$ \\
Water 6 & 3 & & $<\mathrm{LOQ}-0.110$ \\
Water 7 & 4 & & $<\mathrm{LOQ}-0.184$ \\
\hline
\end{tabular}

$\mathrm{n} / \mathrm{a}$, only one offspring in litter.

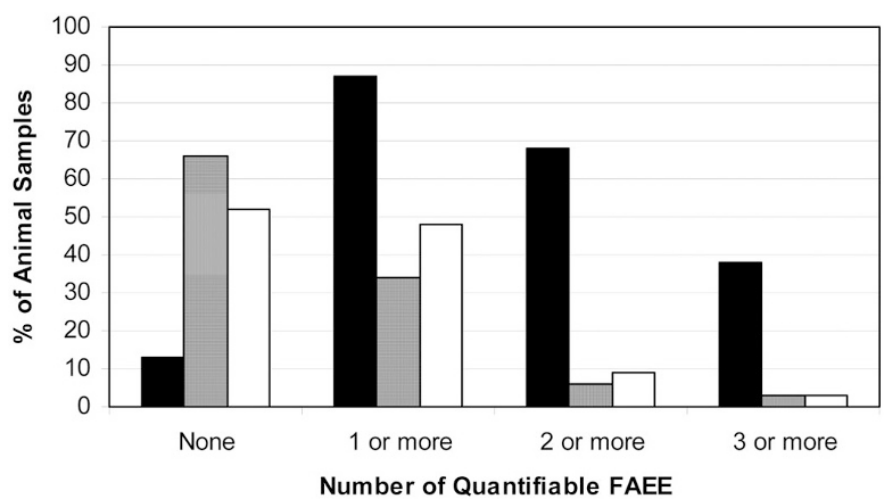

Figure 2. Number of quantifiable FAEE found in each treatment group. Ethanol-treated animals $(n=53)$, (伖) isocaloric sucrose controls $(n=32),(\square)$ isovolumetric water controls $(n=33)$.

of high mass distinctive for each ester (23). As such, a diagnostic ion for each FAEE has been obtained. In choosing CI rather than EI for our analysis, we have been able to develop a method with analytical limits 4-fold lower than those found in current methods $(11,12)$.

Current analytical methods for the measurement of FAEE in hair include four esters-E14, E16, E18, and E18:1 $(11,12)$. For our method, we included two additional esters to our 
analysis, E12 and E16:1. There is a growing body of evidence to suggest that the cumulative analysis of all commonly occurring FAEE in biologic matrices rather than the analysis one specific species of FAEE is a more effective way to identify neonates with suspected prenatal exposure to ethanol (24). Thus, by including more FAEE in the analysis of hair, we may be increasing the reliability of this test to identify individuals, adults and neonates, who have been exposed to heavy levels of alcohol.

Our current method is able to discriminate between adult heavy drinkers and nondrinkers. Wurst et al. (25) have recently reported a dose-response accumulation of FAEE in the hair of adult heavy, social and nondrinkers. It is evident that there is a greater accumulation of FAEE in the hair of individuals who consume greater amounts of alcohol. Our data support such results, which suggest that FAEE in hair are reliable biomarkers to help identify alcohol consumption in adults.

Our results verify for the first time that chronic exposure to alcohol leads to increased levels of FAEE in both maternal and neonatal hair in guinea pigs. Elevated levels of FAEE were repeatedly measured in the hair of chronically dosed pregnant guinea pigs and their pups in comparison to their respective controls. The chronic maternal ethanol regimen used mimicked a binge-type drinking pattern with an apparent peak bloodalcohol concentration (BAC) of $260 \mathrm{mg} / \mathrm{dL}$, more than twice the human legal BAC limit in Canada. It is a dosing regimen shown to cause neurotoxicity in the guinea pig (26). The documented presence of FAEE in the hair of neonatal guinea pigs provides evidence that FAEE do have the ability to accumulate to significant concentrations in the hair matrix of neonates exposed to heavy amounts of alcohol in utero. We confirm that using FAEE in neonatal hair as biomarkers for gestational alcohol exposure in humans is feasible and may be useful in identifying children exposed to alcohol during pregnancy up to three months after birth.

In mammals, normal metabolism leads to the production of small amounts of ethanol and, hence, any method utilizing the measurement of FAEE in body matrix must account for such baseline levels. Indeed, in our study, pups not exposed externally to ethanol displayed FAEE levels well above the detection limit. Similarly, preliminary human studies looking at FAEE levels in the hair of neonates born to nondrinking mothers also reveal quantifiable concentrations, clearly supporting the existence of a basal level of FAEE in neonatal hair (27).

The use of an experimental animal model obviates the most critical obstacle of human studies; the reliance on maternal reports of drinking schedule. By using an animal model, we can administer a highly controlled dose of ethanol and have accurate knowledge of prenatal alcohol exposure. Such a controlled environment has allowed us to evaluate the true relationship between FAEE levels in hair and ethanol exposure. As a result, we have been able to establish the true potential of FAEE becoming accurate and reliable hair biomarkers for in utero alcohol exposure. Future studies can use this novel model to establish the full dose-response curve between steady-state maternal alcohol blood concentrations and neonatal outcomes, a current area of research that is poorly defined.
It is interesting to note the extreme variation of FAEE levels found within pups of the same litter, regardless of treatment group. Within each litter, FAEE hair concentrations could sometimes range from $0.000 \mathrm{pmol} / \mathrm{mg}$ up to $1.776 \mathrm{pmol} / \mathrm{mg}$. Recent studies have shown that at physiologic levels, FAEE cannot be transferred by the human placenta to the fetus. Rather, they are taken up by the placenta and extensively metabolized (28). FAEE are likely produced by the fetus itself from ethanol that has been transferred across the placenta. Thus, they are direct biomarkers reflective of true fetal exposure to ethanol. In guinea pig litters, placentae are not shared; each pup develops throughout gestation within its own placental unit (29). Variations in these units may affect the amount of ethanol transferred to the fetal pup. Consequently, this may lead to variations in the amount of FAEE produced by the fetus and may effect the concentration of FAEE incorporated into neonatal hair. Although the amount of ethanol ingested by the maternal pig is very controlled, such a large variation of FAEE hair concentrations in pups within the same litter may be an indication that each pup has been exposed to a different amount of ethanol. This theory may help to account for the spectrum of toxic effects seen in neonates born to different women claiming to have consumed equivalent amounts of alcohol during pregnancy and may explain why a dose-response for in utero alcohol exposure is so difficult to define. Alternatively, this variability may also reflect variability in fatty acid production and transfer among pups within the same litter.

The documented presence of FAEE in the hair of neonatal guinea pigs provides evidence that FAEE do have the ability to accumulate to significant concentrations in the hair matrix of neonates exposed to heavy amounts of alcohol in utero. Moreover, the accumulation of FAEE in maternal and fetal hair at levels 10-fold higher than those produced by normal diet is very promising in establishing a new screening test for FASD in humans. A neonatal hair test to identify infants exposed to alcohol in utero will revolutionize current FASD diagnostic methodology and provide early intervention and treatment at stages where the effects of alcohol can be minimized and/or reversed.

\section{REFERENCES}

1. Sampson PD, Streissguth AP, Bookstein FL, Little RE, Clarren SK, Dehaene P, Hanson JW, Graham JM Jr 1997 Incidence of fetal alcohol syndrome and prevalence of alcohol-related neurodevelopmental disorder. Teratology 56:317-326

2. Battaglia FC, Howe CJ, Stratton KR, Institute of Medicine, National Institute on Alcohol Abuse and Alcoholism 1996 Fetal Alcohol Syndrome: Diagnosis, Epidemiology, Prevention, and Treatment. National Academy Press, Washington, DC

3. Ebrahim SH, Diekman ST, Floyd RL, Decoufle P 1999 Comparison of binge drinking among pregnant and nonpregnant women, United States, 1991-1995. Am J Obstet Gynecol 180:1-7

4. Abel EL 1996 Fetal Alcohol Syndrome: From Mechanism to Prevention. CRC Press, Boca Raton, FL

5. Russell M, Martier SS, Sokol RJ, Mudar P, Jacobson S, Jacobson J 1996 Detecting risk drinking during pregnancy: a comparison of four screening questionnaires. Am J Public Health 86:1435-1439

6. Laposata M 1999 Fatty acid ethyl esters: current facts and speculations. Prostaglandins Leukot Essent Fatty Acids 60:313-315

7. Best CA, Laposata M 2003 Fatty acid ethyl esters: toxic non-oxidative metabolites of ethanol and markers of ethanol intake. Front Biosci 8:e202-e217

8. Bearer CF 2001 Markers to detect drinking during pregnancy. Alcohol Res Health 25:210-218

9. Klein J, Karaskov T, Korent G 1999 Fatty acid ethyl esters: a novel biologic marker for heavy in utero ethanol exposure: a case report. Ther Drug Monit 21:644-646

10. Ursitti F, Klein J, Koren G 1997 Clinical utilization of the neonatal hair test for cocaine: a four-year experience in Toronto. Biol Neonate 72:345-351 
11. Auwarter V, Sporkert F, Hartwig S, Pragst F, Vater H, Diefenbacher A 2001 Fatty acid ethyl esters in hair as markers of alcohol consumption. Segmental hair analysis of alcoholics, social drinkers, and teetotalers. Clin Chem 47:2114-2123

12. Pragst F, Auwaerter V, Sporkert F, Spiegel K 2001 Analysis of fatty acid ethyl esters in hair as possible markers of chronically elevated alcohol consumption by headspace solid-phase microextraction (HS-SPME) and gas chromatography-mass spectrometry (GC- MS). Forensic Sci Int 121:76-88

13. Clarke DW, Steenaart NA, Slack CJ, Brien JF 1986 Pharmacokinetics of ethanol and its metabolite, acetaldehyde, and fetolethality in the third-trimester pregnant guinea pig for oral administration of acute, multiple-dose ethanol. Can J Physiol Pharmacol 64:1060-1067

14. Zahlten RN, Nejtek ME, Jacobson JC 1981 Ethanol metabolism in guinea pig: in vivo ethanol elimination, alcohol dehydrogenase distribution, and subcellular localization of acetaldehyde dehydrogenase in liver. Arch Biochem Biophys 207:371-379

15. Reynolds JD, Brien JF 1995 Ethanol neurobehavioural teratogenesis and the role of L-glutamate in the fetal hippocampus. Can J Physiol Pharmacol 73:1209-1223

16. Kimura KA, Parr AM, Brien JF 1996 Effect of chronic maternal ethanol administration on nitric oxide synthase activity in the hippocampus of the mature fetal guinea pig. Alcohol Clin Exp Res 20:948-953

17. Catlin MC, Abdollah S, Brien JF 1993 Dose-dependent effects of prenatal ethano exposure in the guinea pig. Alcohol 10:109-115

18. Steenaart NA, Clarke DW, Brien JF 1985 Gas-liquid chromatographic analysis of ethanol and acetaldehyde in blood with minimal artifactual acetaldehyde formation. J Pharmacol Methods 14:199-212

19. Chan D, Bar-Oz B, Pellerin B, Paciorek C, Klein J, Kapur B, Farine D, Koren G 2003 Population baseline of meconium fatty acid ethyl esters among infants of nondrinking women in Jerusalem and Toronto. Ther Drug Monit 25:271-278
20. Bernhardt TG, Cannistraro PA, Bird DA, Doyle KM, Laposata M 1996 Purification of fatty acid ethyl esters by solid-phase extraction and high-performance liquid chromatography. J Chromatogr B Biomed Appl 675:189-196

21. Refaai MA, Nguyen PN, Steffensen TS, Evans RJ, Cluette-Brown JE, Laposata M 2002 Liver and adipose tissue fatty acid ethyl esters obtained at autopsy are postmortem markers for premortem ethanol intake. Clin Chem 48:77-83

22. Jennison CPR, Jennison J 1994 The determination of trace level FAMES using C mode GC/MS. Varian Application Note 37b. Available at http://www.varianinc.com/ image/vimage/docs/products/chrom/apps/gcms37.pdf

23. Moore C, Jones J, Lewis D, Buchi K 2003 Prevalence of fatty acid ethyl esters in meconium specimens. Clin Chem 49:133-136

24. Chan D, Klein J, Koren G 2004 Validation of meconium fatty acid ethyl esters as biomarkers for prenatal alcohol exposure. J Pediatr 144:692

25. Wurst FM, Alexson S, Wolfersdorf M, Bechtel G, Forster S, Alling C, Aradottir S, Jachau K, Huber P, Allen JP, Auwarter V, Pragst F 2004 Concentration of fatty acid ethyl esters in hair of alcoholics: comparison to other biological state markers and self reported-ethanol intake. Alcohol Alcohol 39:33-38

26. Abel EL (ed) 1982 Fetal Alcohol Syndrome. Animal Studies. CRC Press, Boca Raton, FL

27. Caprara D, Klein J, Koren G 2005 Baseline measures of fatty acid ethyl esters in hair of neonates born to abstaining or mild social drinking mothers. Ther Drug Monit (in press)

28. Chan D, Knie B, Boskovic R, Koren G 2004 Placental handling of fatty acid ethyl esters: perfusion and subcellular studies. J Pharmacol Exp Ther 310:75-82

29. Jansson T, Thordstein M, Kjellmer I 1986 Placental blood flow and fetal weight following uterine artery ligation. Temporal aspects of intrauterine growth retardation in the guinea pig. Biol Neonate 49:172-180 